\title{
Phenolic content and antioxidant activity of wholegrain breads from modern and old wheat (Triticum aestivum L.) cultivars and ancestors enriched with wheat sprout powder
}

\author{
Beatrice Falcinelli, ${ }^{1}$ Isabella Calzuola, ${ }^{2}$ Lilia Gigliarelli, ${ }^{3}$ Renzo Torricelli, ${ }^{1}$ Livia Polegri, ${ }^{4}$ \\ Vincenzo Vizioli, ${ }^{5}$ Paolo Benincasa, ${ }^{1}$ Valeria Marsili ${ }^{3}$ \\ ${ }^{1}$ Dipartimento di Scienze Agrarie, Alimentari ed Ambientali, Università di Perugia, Perugia; ${ }^{2}$ Nutraceutical \\ \& Phytochemical Products (NPP) S.r.l, Perugia; ${ }^{3}$ Dipartimento di Biologia Cellulare e Molecolare, \\ Università di Perugia, Perugia; ${ }^{4}$ Parco Tecnologico Agroalimentare dell'Umbria, Todi (PG); ${ }^{5}$ Associazione \\ Italiana per l'Agricoltura Biologica (A.I.A.B.), Roma, Italy
}

\begin{abstract}
In this study, we compared nutritional characteristics of breads from wholegrain flours of three modern cultivars, four old cultivars and one landrace population of common wheat (Triticum aestivum), one Khorasan (Triticum turgidum var turanicum) accession and one einkorn (Triticum monococcum) cultivar. One bread from refined flour was also included. All flours were enriched or not with $5 \%(\mathrm{w}: \mathrm{w})$ of wheat sprout powder (WSP) to obtain enriched breads (EB) or control breads (CB), respectively. Total phenolics and flavonoids, reducing power, radical scavenging and thiobarbituric acid reactive substances production inhibition were measured on bread aqueous extracts. CB from old cultivars were generally higher in phenolic content and antioxidant activity than CB from modern cultivars. All EB showed increased phenolic content and antioxidant activity compared to $\mathrm{CB}$, but the increase varied with the source flour, despite WSP supplementation was the same for all breads. In particular, the increase in phenolic content was much relevant for EB of modern cultivars.
\end{abstract}

Correspondence: Valeria Marsili, Dipartimento di Biologia Cellulare e Molecolare, Università di Perugia, via Elce di Sotto 8, 06123 Perugia, Italy.

E-mail: valeria.marsili@unipg.it

Key words: Aqueous extract; flavonoids; reducing power; radical scavenging; thiobarbituric acid reactive substances.

Acknowledgements: this research was supported by the Progetto PSR Regione Umbria - Mis. 1.2.4. Frumenti antichi per pani nuovi.

Received for publication: 12 February 2018.

Revision received: 22 June 2018.

Accepted for publication: 25 June 2018.

(C) Copyright B. Falcinelli et al., 2018

Licensee PAGEPress, Italy

Italian Journal of Agronomy 2018; 13:1220

doi:10.4081/ija.2018.1220

This article is distributed under the terms of the Creative Commons Attribution Noncommercial License (by-nc 4.0) which permits any noncommercial use, distribution, and reproduction in any medium, provided the original author(s) and source are credited.

\section{Introduction}

Bread is a basic food in human diet. In developed countries bread is mainly made with refined flour, which is low in fibre, bioactive compounds and antioxidants (Dziki et al., 2014), because these compounds are mainly present in the bran. Moreover, modern wheat cultivars have been obtained with breeding programs principally aimed at increasing yield, while neglecting bioactive compounds (Leoncini et al., 2012). Today, there is a growing interest towards foods high in bioactive compounds for their benefits in human health such as free radical scavenging properties or anticancer activity (Dziki et al., 2014). In this regard, old wheat cultivars are more and more reconsidered (Ghiselli et al., 2016). Leoncini et al. (2012) found that grains of Verna and Gentil Rosso were higher in phenolic compounds and antioxidant activity compared to grains of a modern cultivar and Migliorini et al. (2016), reported that breads from old wheat varieties (e.g., Verna, Gentil Rosso) were particularly appreciated by consumers. There is also an interest towards ancient Triticum species. It is the case of the Khorasan (Triticum turgidum var turanicum Jakubz), which is rich in carotenoids like lutein and zeaxanthine, both involved in eye health (Abdel-Aal and Rabalski, 2013). Similarly, einkorn (Triticum monococcum L.) is rich in antioxidant compounds like bound phenolics (Benincasa et al., 2015), carotenoids, tocols, alkylresorcinols and phytosterols (Hidalgo and Brandolini, 2014). For these old cultivars, milling procedures often include the bran in the flour, with well known health benefits (Dziki et al., 2014), and single-cultivar products represent a sort of brand with a relevant niche-market. Actually, single-cultivar products are expected to have standard traits, although the environment (i.e., the location and season weather) may strongly affect the outcome. In fact, when comparing flours and their products, source grains should come from the same environment and cultivation condition. Moreover, to meet consumers' expectance for this kind of niche products, the grains should better be obtained from crops grown organically.

An alternative means to improve the nutritional value of breads is represented by the supplementation of flours with plants extracts and plant parts (Dziki et al., 2014), including sprout powder (Gawlik-Dziki et al., 2014, 2017; Świeca et al., 2017). Sprouts, i.e., the young seedlings of many species are a new trend of healthy food. In particular, sprouts from Triticum species have been found to be high in bioactive compounds (e.g., phytochemicals, phospholipids, reducing glycosides, and low molecular weight peptides) (Calzuola et al., 2004; Lucci et al., 2013; Benincasa et al., 2015; Falcinelli et al., 2017; Stagnari et al., 
2017) having antioxidant, antimutagenic, and anti-ageing properties (Falcioni et al., 2002; Calzuola et al., 2004; Amici et al., 2008; Lucci et al., 2013). Sprouts are generally produced homemade or for ready-to-eat market, but can also be dried and ground to a fine powder to be used as supplements. The use of wheat sprout powder (WSP) to enrich wheat flours has been proposed recently (Žilić et al., 2014; Gawlik-Dziki et al., 2017; Świeca et al., 2017). In particular, Gawlik-Dziki et al. (2017) replaced a refined wheat flour with $5,10,15,20 \%$ (w:w) of WSP and observed an increase of phenolics in breads, although they warned that the supplementation of WSP at high concentration may negatively influence the baking properties (Abderrahim et al., 2012). The WSP supplementation may be expected to have different nutritional effects on breads depending on the source flour, i.e., refined $v s$ wholegrain and modern $v s$ old varieties.

Thus, the aim of this study was to investigate the effect of WSP supplementation on the nutritional and sensory characteristics of breads obtained from wholegrain flours of modern and old cultivars of common wheat and ancestors, grown organically in the same field trial.

\section{Materials and methods}

\section{Provenance of grains used for breads}

Ten wholegrain flours from single-cultivar grains were compared (Table 1): Bologna, Blasco, Bolero (modern Triticum aestivum cultivars), Abbondanza, Gentil Rosso, San Pastore, Verna (old T. aestivum cultivars), Biancola (T. aestivum landrace population), Khorasan (Triticum turgidum, var turanicum), and Einkorn (Triticum monococcum, cv. Monlis). A Bologna refined flour (Bologna-REF) was also included as control. The seeds of most varieties were provided by the Associazione Italiana Agricoltura Biologica (AIAB). Seeds of the cultivar Monlis were provided by Prometeo s.r.l. (Canavaccio, Pesaro Urbino, Italy). All varieties were cultivated in the year 2014-2015 in an organic field trial located in S. Andrea di Agliano-PG-Italy $\left(43^{\circ} 02^{\prime} \mathrm{N}, 12^{\circ} 24^{\prime} \mathrm{E}, 127\right.$ $\mathrm{m}$ a.s.1.) under the control of the Department of Agricultural, Food and Environmental Sciences of University of Perugia. The field experimental design was a randomised block with four replicates. Each experimental unit (plot) consisted of 8 rows $6 \mathrm{~m}$ long. Fertilisation was carried out with manure $(30 \mathrm{~kg} \mathrm{~N} / \mathrm{ha})$ applied at tillering. Each cultivar was harvested when it reached complete maturity.

\section{Production of wheat sprout powder and breads}

The sprouts used for producing the WSP were supplied by NPP s.r.l., a spin-off company of the University of Perugia (Italy). Sprouts were obtained from grains of the cultivar Bologna following the method reported by Calzuola et al. (2004). Grains were sown on sterilised soft agar (0.8-1\%) in plastic boxes for food and placed in a growth chamber at $20^{\circ} \mathrm{C}$. Sprouts were collected 5 days after sowing, with the shoots about $5 \mathrm{~cm}$ long, they were dehydrated under a gentle and continuous flow of dehumidified air at $30^{\circ} \mathrm{C}$ for $48 \mathrm{~h}$ and powdered. The WSP was stored under vacuum at room temperature and used to enrich breads.

The control bread (CB) dough of each Triticum treatment was prepared by mixing $500 \mathrm{~g}$ of flour with $10 \mathrm{~g}$ of salt, $10 \mathrm{~g}$ of sugar, $5 \mathrm{~g}$ of yeast and $300 \mathrm{~mL}$ of water. The enriched bread (EB) dough was prepared with the same recipe but replacing $25 \mathrm{~g}$ of flour with $25 \mathrm{~g}$ of WSP. Each dough was kept at $4^{\circ} \mathrm{C}$ for $12 \mathrm{~h}$ and baked in oven at $200^{\circ} \mathrm{C}$. After $3 \mathrm{~h}$, breads were cut into slices and a representative subsample of $50 \mathrm{~g}$ was dried at room temperature for 48 $\mathrm{h}$ and finely ground for aqueous extraction and chemical analyses, which were performed in triplicate.

\section{Aqueous extraction}

Aqueous extractions were achieved following the method of Calzuola et al. (2004). The WSP and ground CB and EB were mixed with distilled water $(1: 5 \mathrm{w} / \mathrm{v})$ and homogenised five times by a mixer, alternating $30 \mathrm{~s}$ of homogenisation and $30 \mathrm{~s}$ pause to prevent heating. Extracts were then centrifuged at $7000 \mathrm{rpm}$ for 30 $\min$ at $4{ }^{\circ} \mathrm{C}$ and the supernatants were stored at $-20^{\circ} \mathrm{C}$ in small aliquots. Before the chemical analysis, aliquots were de-frozen and centrifuged at 10,000 rpm for $10 \mathrm{~min}$ at room temperature.

\section{Total phenolic and flavonoid contents}

The measurement of total phenolic content (TPC) was performed with phosphomolybdic-phosphotungstic acid reagent, according to the method of Singleton and Rossi (1965). $20 \mu \mathrm{L}$ of extracts were mixed with $50 \mu \mathrm{L}$ of Folin-Ciocalteu reagent, $100 \mu \mathrm{L}$ of $20 \% \mathrm{Na}_{2} \mathrm{CO}_{3}(\mathrm{w} / \mathrm{v}), 830 \mu \mathrm{L}$ of deionised water and then incubated for $30 \mathrm{~min}$ at room temperature. For each sample, a blank control was prepared replacing the Folin-Ciocalteu reagent with the same volume of water. Absorbance was read at $760 \mathrm{~nm}$ by a spectrophotometer (Varian Cary 100 Scan) and values were evaluated as the difference between samples and their own blank control. The measured values were compared by using a calibration curve obtained with different concentrations of gallic acid as standard, and expressed as milligrams of gallic acid equivalents per grams of

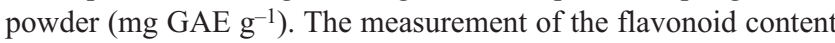

Table 1. Details on the Triticum cultivars and accessions used in this study.

\begin{tabular}{|c|c|c|c|c|}
\hline Species & Ploidy & Variety/accession & Modern/old & Year of release \\
\hline Triticum aestivum $\mathrm{L}$. & Hexaploid & $\begin{array}{c}\text { Bologna } \\
\text { Blasco } \\
\text { Bolero } \\
\text { Abbondanza } \\
\text { Gentil Rosso } \\
\text { Biancola } \\
\text { San Pastore } \\
\text { Verna }\end{array}$ & $\begin{array}{c}\text { Modern } \\
\text { Modern } \\
\text { Modern } \\
\text { Old } \\
\text { Old } \\
\text { Landrace } \\
\text { Old } \\
\text { Old }\end{array}$ & $\begin{array}{c}2002 \\
2002 \\
1990 \\
1930 \\
1911 \\
- \\
1929 \\
1953\end{array}$ \\
\hline Triticum turgidum var. turanicum Jakubz & Tetraploid & Khorasan & Ancestor & - \\
\hline Triticum monococcum $\mathrm{L}$. & Diploid & Monlis & Ancestor & - \\
\hline
\end{tabular}


(FC) was performed by the colorimetric (aluminium chloride) method (Chang et al., 2002). Each extract $(50 \mu \mathrm{L})$ was mixed with $450 \mu \mathrm{L}$ of distilled water and $30 \mu \mathrm{L}$ of $5 \%$ sodium nitrite $\left(\mathrm{NaNO}_{2}\right)$ and incubated at room temperature for $5 \mathrm{~min}$. Aluminium chloride $\left(\mathrm{AlCl}_{3}\right) 1 \%(300 \mu \mathrm{L})$ was added, and the mix was incubated for 6 min at room temperature. Sodium hydroxide $(\mathrm{NaOH}) 1 \mathrm{M}(200$ $\mu \mathrm{L}$ ) was finally added and the absorbance of all samples was read at $510 \mathrm{~nm}$ wavelength. The values were computed by utilising the average of the dose-responses obtained with quercetin as standard, and expressed as milligrams of quercetin equivalents per grams of powder (mg QE g $\left.{ }^{-1}\right)$.

\section{Reducing power}

The reducing power (RP) of extracts was measured using potassium ferricyanide as reagent, following the method of Yen and Chen (1995). An aliquot of $250 \mu \mathrm{L}$ of extract was mixed with an equal volume of $0.2 \mathrm{M}$ phosphate buffer, $\mathrm{pH} 6.6$ and $1 \%$ potassium ferricyanide. The mixture was incubated at $50^{\circ} \mathrm{C}$ for $20 \mathrm{~min}$. Then, an equal volume of $1 \%$ trichloroacetic acid was added and the mixture was centrifuged at $6000 \mathrm{rpm}$ at room temperature for $10 \mathrm{~min}$. The upper layer of solution was mixed with distilled water and $0.1 \% \mathrm{FeCl}_{3}$ at a ratio of 1:1:2 and the absorbance was measured at $700 \mathrm{~nm}$. The RP was expressed as $\mu \mathrm{mol}$ of reduced potassium ferricyanide, which correspond to a half of optical density (700 nm), according to Calzuola et al. (2004).

\section{Superoxide radical scavenging assay (nitrotetrazolium blue chloride assay)}

The measurement of superoxide radical scavenging (RS) activity was carried out according to Kirby and Schmidt (1997). An aliquot of $25 \mu \mathrm{L}$ of $15 \mathrm{mM} \mathrm{Na} \mathrm{NDDA}_{2}$ in buffer $(50 \mathrm{mM}$ $\mathrm{KH}_{2} \mathrm{PO}_{4} / \mathrm{KOH}, \mathrm{pH} 7.4$ ), $63 \mu \mathrm{L}$ of $0.6 \mathrm{mM}$ nitrotetrazolium blue chloride (NBT) in buffer, $38 \mu \mathrm{L}$ of $3 \mathrm{mM}$ hypoxanthine in $50 \mathrm{mM}$ $\mathrm{KOH}, 62.5 \mu \mathrm{L}$ of extract, and $137.5 \mu \mathrm{L}$ of buffer were mixed in 96well microplates (Falcon). In the blank, the extract was replaced by an equal volume of water. The reaction was started by adding 25 $\mu \mathrm{L}$ of xanthine oxidase solution in buffer ( 1 unit in $10 \mathrm{~mL}$ of buffer) to the mixture. The reaction mixture was incubated at $25^{\circ} \mathrm{C}$ and the absorbance at $570 \mathrm{~nm}$ was determined every $1 \mathrm{~min}$ in the first $5 \mathrm{~min}$ and then every $5 \mathrm{~min}$ until $60 \mathrm{~min}$ using a plate reader (Labsystems Multiskan MS). The RS activity was measured as inhibition of NBT reduction. Superoxide can reduce NBT to monoformazan via one electron transfer, and this reaction can be monitored spectrophotometrically at $570 \mathrm{~nm}$. The absorbance at the sixtieth minute was considered as the plateau value and expressed as percentage of inhibition of oxygen superoxide.

Inhibition \% (I \%) of oxygen superoxide $\left.=100-\frac{(\mathrm{A} x}{\mathrm{A}_{\mathbf{0}}} \mathrm{100}\right)$

where $\mathrm{A}$ is the absorbance of the sample and $\mathrm{A}_{0}$ is the absorbance of control.

\section{Inhibition of thiobarbituric acid reactive substances production}

The capacity of extracts to inhibit the production of thiobarbituric acid reactive substances (TBARS) from degradation of sodium benzoate was evaluated following the method developed by Koracevic et al. (2001). Such inhibition was calculated as the difference of activity between the sample $\left(\mathrm{S}_{1}\right)$ and its blank control $\left(\mathrm{S}_{0}\right)$. A standardised solution of Fe-EDTA complex was prepared mixing equal volumes of $2 \mathrm{mM}$ EDTA and $2 \mathrm{mM} \mathrm{FeCl}_{3}$ and incubating it for $1 \mathrm{~h}$ at room temperature. An aliquot of $100 \mu \mathrm{L}$ of extract was incubated at $37^{\circ} \mathrm{C}$ for $1 \mathrm{~h}$ in the presence of $400 \mu \mathrm{L}$ of $0.1 \mathrm{M}$ sodium phosphate buffer $\mathrm{pH} 7.4,500 \mu \mathrm{L}$ of $10 \mathrm{mM}$ sodium benzoate, $200 \mu \mathrm{L}$ of Fe-EDTA complex, $200 \mu \mathrm{L} 10 \mathrm{mM} \mathrm{H}_{2} \mathrm{O}_{2}$. In the reference control, the extract was replaced by an equal volume of the same sodium phosphate buffer. Acetic acid 20\% (1 mL) was added prior incubation to the $\mathrm{S}_{0}$ samples. After incubation, $1 \mathrm{~mL}$ of $20 \%$ acetic acid was added to samples $\mathrm{S}_{1}$, and $1 \mathrm{~mL}$ of $0.8 \%$ thiobarbituric acid in $50 \mathrm{mM} \mathrm{NaOH}$ was added to all samples. Samples were then incubated at $100^{\circ} \mathrm{C}$ for $10 \mathrm{~min}$ and then cooled in ice, and the absorbance was read at $532 \mathrm{~nm}$ wavelength. $\mathrm{S}_{0}$ readings were detracted from $S_{1}$ readings and resulting values (A) were expressed as percentage of inhibition of TBARS production as compared to the reference control $\left(\mathrm{A}_{0}\right)$.

Inhibition $\%(\mathrm{I} \%)$ of TBARS production $\left.=100-\frac{(\mathrm{A}}{\mathrm{A}_{\mathbf{0}}} \times 100\right)$

where $\mathrm{A}$ is the absorbance of the sample and $\mathrm{A}_{0}$ is the absorbance of control.

\section{Statistical analysis}

All chemical analyses were carried out in triplicate for one sample of each bread. Data were subjected to analysis of variance and means were compared by using Fisher's LSD.

\section{Results and discussion}

\section{Phenolic content in wheat sprout powder and breads}

The WSP had very high values of TPC $(1.83 \pm 0.272 \mathrm{mg}$ GAE $\left.\mathrm{g}^{-1}\right)$ and $\mathrm{FC}\left(0.88 \pm 0.035 \mathrm{mg} \mathrm{QE}^{-1}\right)$. The high TPC values of WSP are in line with those observed in previous experiments (Benincasa et al., 2015).

In control breads (CB), TPC (Figure 1A) and FC (Figure 1B) values were always lower than in WSP, except for the TPC of Gentil Rosso, which reached $2 \mathrm{mg} \mathrm{g}^{-1}$. Among CB, old Triticum cultivars and accessions had TPC values generally higher than modern cultivars: besides Gentil Rosso, also Abbondanza, Khorasan and Biancola showed TPC over $1 \mathrm{mg} \mathrm{GAE} \mathrm{g}^{-1}$ of bread. Differences in FC among CB followed a trend similar to that of TPC, with Gentil Rosso standing out for a very high FC value. Higher TPC and FC values of old cultivars and accessions clearly arise from the higher phenolic concentrations of grains and wholegrain flours reported by Leoncini et al. (2012) and Migliorini et al. (2016), who included some of the cultivars used here, such as Gentil Rosso and Verna. Migliorini et al. (2016) observed values

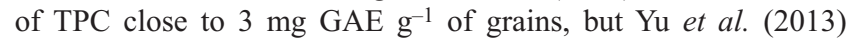
reported that a relevant decrease occurred in the TPC value passing from wholegrain flours to breads, probably due to the loss of some labile phenolic acids (Abdel-Aal and Rabalski, 2013) and vitamins with baking. It is to notice that we used an aqueous extraction, which is able to extract all hydrophilic antioxidants, vitamins and peptides included (Calzuola et al., 2004), which may react with the Folin-Ciocalteu reagent (Singleton et al., 1999). Actually, water extraction is considered biologically meaningful, since human feeding usually implies water extracts. Moreover, water is nontoxic and gives advantages for certification and safety (Wong et al., 2005). The FC values of our breads were much lower than the values reported by Migliorini et al. (2016), but differently from TPC, there is no reference to compare the decrease of FC caused by baking. Literature dealing with flavonoids in wheat bread is 
substantially in line with the FC level of our $\mathrm{CB}$ although none included old wheat cultivars and accessions, most used organic extractions, some detected only single flavonoid compounds like quercetin and rutin (Lin et al., 2009), and some used a different standard (i.e., catechin) (Irakli et al., 2015). A significant difference was recorded between the refined and wholegrain $\mathrm{CB}$ of Bologna, confirming results obtained for other cultivars by $\mathrm{Yu}$ et al. (2013).

WSP-enriched breads (EB) showed a general increase of both TPC (Figure 1A) and FC (Figure 1B) compared to CB, with few exceptions for FC (Gentil Rosso and Biancola, where there was no change, and Einkorn, where there was a slight decrease). The expected general increase of phenolic compounds in EB confirms evidences from Gawlik-Dziki et al. (2017), who also supplemented wheat flour with 5 to $20 \%$ (w:w) of WSP, and from GawlikDziki et al. (2014) who replaced wheat flour with $1 \%$ to $5 \%$ of broccoli sprout powder. In both works, these authors found that the increase of phenolic compounds was not proportional to the ratio of WSP supplementation and that replacing flour with 5\% (w:w) of sprout powder represented a good compromise to increase phenolic content without worsening baking and sensory characteristics of breads. Changes in absolute values of TPC and FC from CB to EB varied with the treatment, despite WSP supplementation was the same for all breads. In particular, the increase of TPC was much relevant for EB of modern cultivars. The increase of both TPC and FC values from $\mathrm{CB}$ to $\mathrm{EB}$ was much relevant for Bologna refined, which reached values comparable or even higher than $\mathrm{CB}$ from most cultivars. Thus, the effect of WSP supplementation appears not strictly additive. Several factors may come into play to explain this, in particular the interaction between the phenolic compounds of the WSP, the phenols present in the flour, the other components of the flour and the thermal treatment. Turkmen et al. (2005) demonstrated that phenols in plant tissues may decrease or even increase after a thermal treatment, depending on the matrix. In fact, the thermal treatment may cause: i) the release of antioxidants by destruction of cell and subcellulars walls; ii) the production of new radical scavenging antioxidants from thermal chemical reactions; iii) the inactivation of oxidative enzymes suppressing antioxidants; and iv) the formation of novel antioxidant compounds (i.e., Maillard reaction products) (Jimenèz-Monreal et al., 2009). For these reasons, it has been reported that the effects of thermal processing depend on polyphenols concentration and their chemical structure, oxidation level, localisation in the cell, interaction with other food components and type of thermal process applied (van Boekel et al., 2010). Similar comments can be addressed for the increase of FC in EB. The higher increase of TPC in EB from modern cultivars and even from Bologna-REF is relevant, because it makes of WSP supplementation a powerful tool to improve nutritional quality of wheat cultivars which are more agronomically suitable and productive and of white breads which are traditionally widespread and available in the market.

\section{Antioxidant activity of breads}

In $\mathrm{CB}$, either the reducing power (RP) (Figure 2) or the radical scavenging (RS) (Figure 3) or the TBARS production inhibition (Figure 4) were generally higher in old/ancient Triticum cultivars/accessions than in modern cultivars, with Gentil Rosso and Abbondanza showing the highest values for all the three assays. Khorasan and Biancola showed high values for RP and TBARS but not for RS. Bologna-REF did not differ much from Bologna. The high values of RP, RS and TBARS of breads from old cultivars is in line with data reported by Leoncini et al. (2012) for the grains, and the lack of difference between the refined and
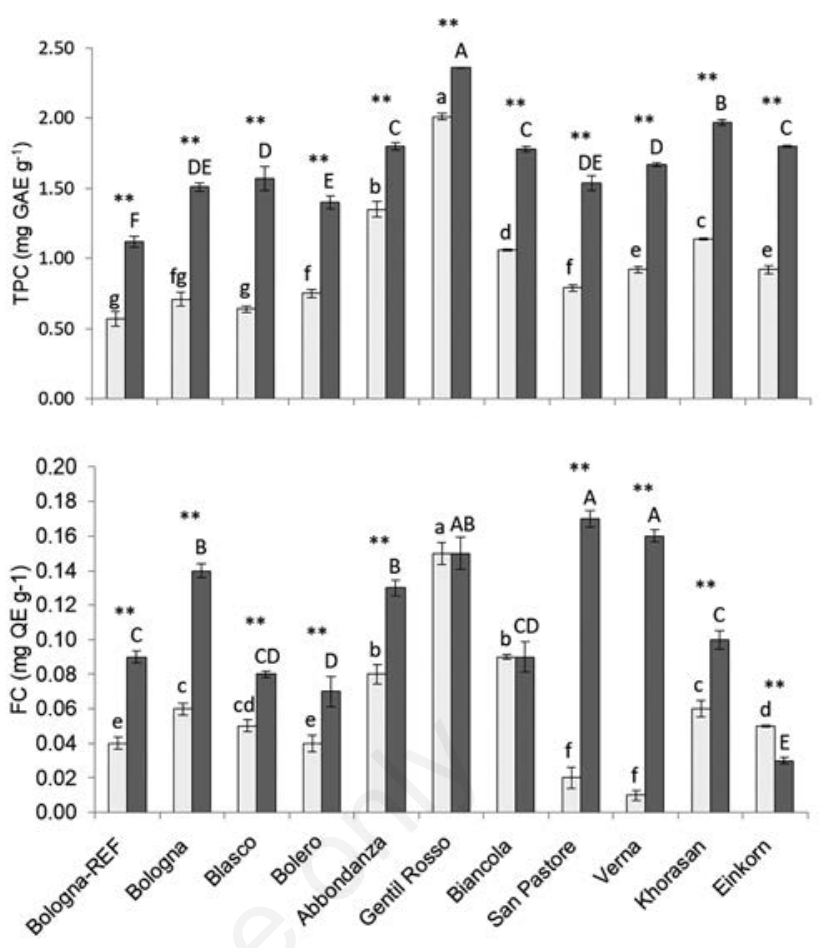

Figure 1. A) Total phenolic content (TPC) (mg GAE $\mathrm{g}^{-1}$ bread), and B) flavonoid content (FC) ( $\mathrm{mg} \mathrm{QE}^{-1}$ bread) of extracts from control breads (CB) ( $\square$ ) and WSP-enriched breads (EB) ( $\square$ ) made with flours (all wholegrain except for one refined, BolognaREF) from modern and old cultivars of common wheat and ancestors. Vertical bars represent \pm standard error. Different letters indicate significant differences (Fisher's $L S D, P<0.05$ ): lower case letters are for comparison within $\mathrm{CB}$ and upper case letters for comparison within EB. Asterisks indicate significant differences $\left({ }^{* *} \mathrm{P}<0.01,{ }^{*} \mathrm{P}<0.05\right)$ for each $\mathrm{CB}$ vs $\mathrm{EB}$ comparison (i.e., within each pair of columns).

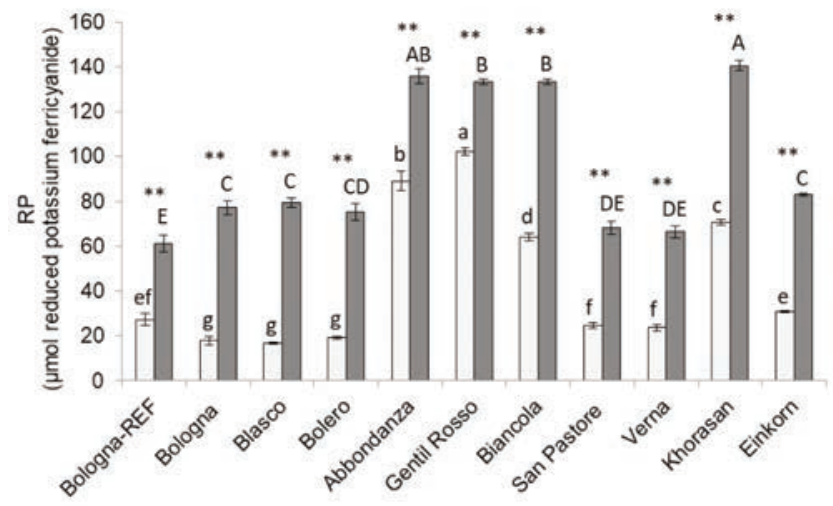

Figure 2. Total reducing power (RP) ( $\mu$ mol reduced potassium ferricyanide $\mathrm{g}^{-1}$ bread) of extracts from control breads $(\square)$ and wheat-sprout-powder enriched breads $(\square)$ made with flours (all wholegrain except for one refined, Bologna-REF) from modern and old cultivars of common wheat and ancestors. Vertical bars represent \pm standard error. Different letters indicate significant differences (Fisher's LSD, $\mathrm{P}<0.05$ ): lower case letters are for comparison within $\mathrm{CB}$ and upper case letters for comparison within EB. Asterisks indicate significant differences $\left({ }^{* *} \mathbf{P}<0.01,{ }^{*} \mathbf{P}<0.05\right)$ for each $\mathrm{CB} v \boldsymbol{\mathrm { EB }}$ comparison (i.e., within each pair of columns). 
wholegrain bread of Bologna is in line with results by Yu et al. (2013), who tested five different wheat genotypes. Of course, the thermal treatment caused by baking will have caused changes in antioxidants, but there is no reference to make a comparison. However, based on results from Yu et al. (2013), baking is expected to reduce antioxidant activity by $20-40 \%$ depending on wheat cultivars. The literature on breads reports antioxidant activities mainly evaluated with FRAP, DPPH and ABTS methods, which generally test same antioxidant properties and give comparable results (Thaipong et al., 2006). Differently, our three methods analyse different antioxidant properties, i.e. the ability of a sample to

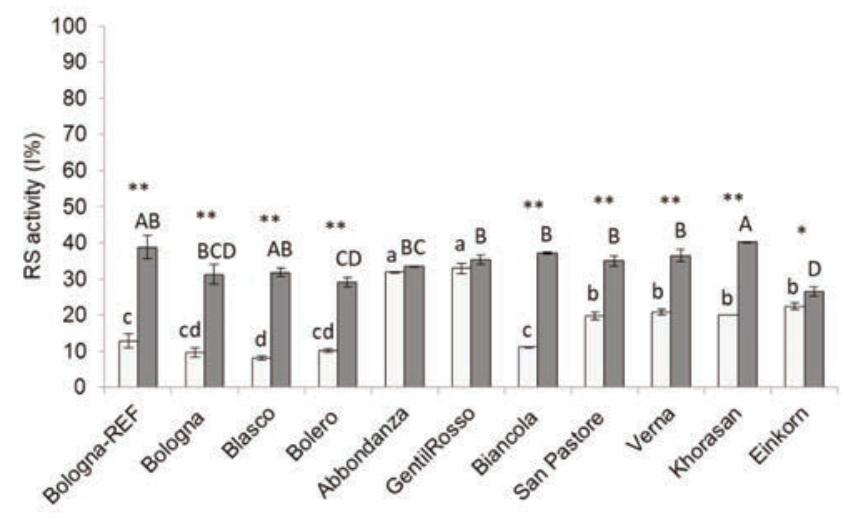

Figure 3. Radical scavenging (RS) activity (\%) of extracts from control breads $(\square)$ and wheat-sprout-powder enriched breads ( $\square$ ) made with flours (all wholegrain except for one refined, Bologna-REF) from modern and old cultivars of common wheat and ancestors. Vertical bars represent \pm standard error. Different letters indicate significant differences (Fisher's LSD, $\mathrm{P}<0.05$ ): lower case letters are for comparison within $C B$ and upper case letters for comparison within EB. Asterisks indicate significant differences $\left({ }^{* *} \mathrm{P}<0.01,{ }^{*} \mathrm{P}<0.05\right)$ for each $\mathrm{CB}$ vs $\mathrm{EB}$ comparison (i.e., within each pair of columns).

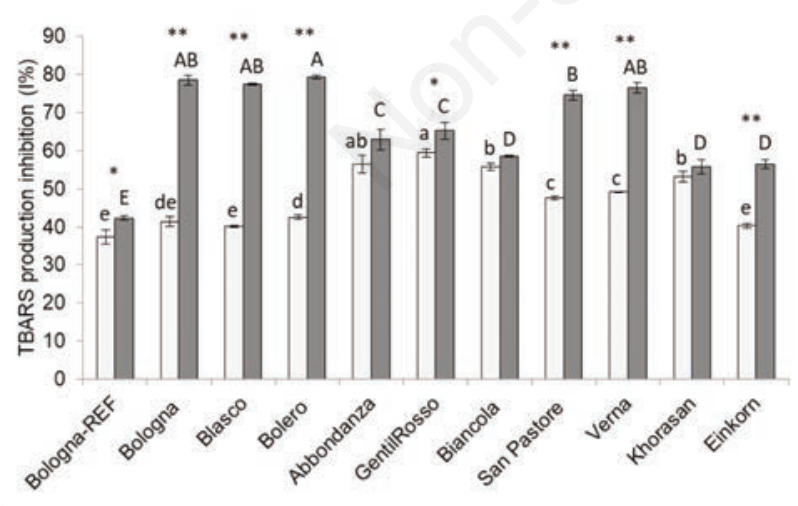

Figure 4. TBARS production (lipid peroxidation) inhibition (\%) of extracts from control breads $(\square)$ and wheat-sprout-powder enriched breads ( $\square$ ) made with flours (all wholegrain except for one refined, Bologna-REF) from modern and old cultivars of common wheat and ancestors. Vertical bars represent \pm standard error. Different letters indicate significant differences (Fisher's LSD, $P<0.05$ ): lower case letters are for comparison within $C B$ and upper case letters for comparison within EB. Asterisks indicate significant differences $\left({ }^{* *} \mathrm{P}<0.01,{ }^{*} \mathrm{P}<0.05\right)$ for each $\mathrm{CB}$ vs $\mathrm{EB}$ comparison (i.e., within each pair of columns). reduce $\mathrm{Fe}^{3+}$ (RP) (Yen and Chen, 1995), or to scavenge the superoxide $\left(\mathrm{O}_{2}^{-}\right)$(RS) (Kirby and Schmidt, 1997) or the hydroxyl radical $\left(\mathrm{OH}^{-}\right)$(TBARS) (Koracevic et al., 2001). Thus, our three tests give a broad picture of the bread antioxidant activity. The substantial agreement of the three tests for CB indicates that all the antioxidant pool of source grains contribute to the overall antioxidant activity of breads. In particular only the RP of $\mathrm{CB}$ was correlated with the phenolic compounds $\left(\mathrm{R}^{2}=0.83\right.$ for TPC and 0.67 for FC), which means that other antioxidant compounds are involved in the scavenging of superoxide (RS) and hydroxyl radical (TBARS).

All EB showed increased antioxidant activities compared to CB. In particular, the RP was much higher in EB of Gentil Rosso, Abbondanza, Biancola and Khorasan than in the other cultivars (Figure 2), while, unexpectedly, TBARS production inhibition of EB from these four cultivars showed lower values than EB from several other cultivars, including the modern ones (Figure 4). The RS was not much different among EB treatments (Figure 3). In general, the highest relative increases of antioxidant activities were recorded in those treatments having the lowest values for $\mathrm{CB}$, in particular the modern cultivars. The different trends of the three tests for the EB indicates the substantial effect of WSP supplementation in enriching breads with a different pool of antioxidant molecules. Calzuola et al. (2004) reported several low-molecular weight compounds in wheat sprouts having antioxidant activity, like polyphenols, peptides, reducing glycosides, and found that many of them are resistant to heating. The non-additive effect of WSP supplementation for the different breads has to be interpreted in light of the above said interaction between the WSP components with the source flour components and the thermal treatment of baking. The most relevant result of this work is that the increase in bread antioxidant activity due to the addition of WSP was higher for breads having low antioxidant activity. Therefore, WSP supplementation may represent a valuable means to improve the nutritional value of breads even in case of low quality source grains.

\section{Conclusions}

Results indicate that, in many cases, breads from old cultivars and accessions had higher phenolic content and antioxidant activity than breads from modern cultivars, but differences were not always relevant. All wheat-sprout-powder enriched breads showed higher phenolic content and antioxidant activity compared to control breads, but the increase varied with the source flour, despite the wheat sprout powder supplementation was the same for all breads. In particular, the increase of total phenolic content was much relevant for enriched breads of modern cultivars. Overall, enriching breads with $5 \%$ of wheat sprout powder may represent a valuable means to increase the nutritional value of breads and their economic value in the healthy food market.

\section{References}

Abdel-Aal ES, Rabalski I, 2013. Effect of baking on free and bound phenolic acids in wholegrain bakery products. J. Cereal Sci. 57:312-8.

Abderrahim F, Huanatico E, Repo-Carrasco-Valencia R, Arribas SM, Gonzalez MC, Condezo-Hoyos L, 2012. Effect of germination on total phenolic compounds, total antioxidant capacity, maillard reaction products and oxidative stress markers in 
canihua (Chenopodium pallidicaule). J. Cereal Sci. 56:410-7.

Amici M, Bonfili L, Spina M, Cecarini V, Calzuola I, Marsili V, Angeletti M, Fioretti E, Tacconi R, Gianfranceschi GL, Eleuteri AM, 2008. Wheat sprout extract induces changes on 20S proteasomes functionality. Biochimie 90:790-801.

Benincasa P, Galieni A, Manetta AC, Pace R, Guiducci M, Pisante M, Stagnari F, 2015. Phenolic compounds in grains, sprouts and wheatgrass of hulled and non-hulled wheat species. J. Sci. Food Agric. 95:1795-803.

Calzuola I, Marsili V, Gianfranceschi GL, 2004. Synthesis of antioxidants in wheat sprouts. J. Agric. Food Chem 52:5201-6.

Chang CC, Yang MH, Wen HM, Chern JC, 2002. Estimation of total flavonoid content in propolis by two complementary colorimetric methods. J. Food Drug Anal. 10:178-82.

Dziki D, Różylo R, Gawlik-Dziki U, Świeca M, 2014. Current trends in the enhancement of antioxidant activity of wheat bread by the addition of plant materials rich in phenolic compounds. Trends Food Sci. Technol. 40:48-61.

Falcinelli B, Benincasa P, Calzuola I, Gigliarelli L, Lutts S, Marsili V, 2017. Phenolic content and antioxidant activity in raw and denatured aqueous extracts from sprouts and wheatgrass of einkorn and emmer obtained under salinity. Molecules 22:2132.

Falcioni G, Fedeli D, Tiano L, Calzula I, Mancinelli L, Marsili V, Gianfranceschi GL, 2002. Antioxidant activity of wheat sprout extracts in vitro: inhibition of DNA oxidative damage. J. Food Sci. 67:2918-22.

Gawlik-Dziki U, Dziki D, Pietrzak W, Nowak R, 2017. Phenolic acids profile and antioxidant properties of breads enriched with sprouted wheat flour. J. Food Biochem. [Epub ahead of print].

Gawlik-Dziki U, Świeca M, Dziki D, Sęczyk Ł, Złotek U, Różylo R, Kaszuba K, Ryszawy D, Czyż J, 2014. Anticancer and antioxidant activity of bread enriched with broccoli sprouts. Biomed Res. Int. 2014:608053.

Ghiselli L, Rossi E, Whittaker A, Dinelli G, Baglio AP, Andrenelli L, Benedettelli S, 2016. Nutritional characteristics of ancient Tuscan varieties of Triticum aestivum L. Ital. J. Agron. 11:137-245.

Hidalgo A, Brandolini A, 2014. Nutritional properties of einkorn wheat (Triticum monococcum L.). J. Sci. Food Agric. 94:601-12.

Irakli M, Katsantonis D, Kleisiaris F, 2015. Evaluation of quality attributes, nutraceutical components and antioxidant potential of wheat bread substituted with rice bran. J. Cereal Sci. 65:74-80.

Jimenèz-Monreal AM, Garcìa-Diz L, Martìnez-Tomè M, Mariscal M, Murcia MA, 2009. Influence of cooking methods on antioxidant activity of vegetables. J. Food Sci. 74:97-103.

Kirby AJ, Schmidt RJ, 1997. The antioxidant activity of Chinese herbs for eczema and of placebo herbs. J. Ethnopharmacol. 56:103-8.

Koracevic D, Koracevic G, Djordjevic V, Andrejevic S, Cosic V, 2001. Method for the measurement of antioxidant activity in human fluids. J. Clin. Pathol. 54:356-61.

Leoncini E, Prata C, Malaguti M, Marotti I, Segura-Carretero A, Catizone P, Dinelli G, Hrelia S, 2012. Phytochemical profile and nutraceutical value of old and modern common wheat cultivars. PLoS One 7:1-13.

Lin LY, Liu HM, Yu YW, Lin SD, Mau JL, 2009. Quality and antioxidant property of buckwheat enhanced wheat bread. Food Chem. 112:987-91.

Lucci P, Pacetti D, Calzuola I, Marsili V, Perni S, Giavarini F, Frega NG, Gianfranceschi GL, 2013. Characterization of phospholipid molecular species and peptide molecules in wheat sprout hydroalcoholic extract. J. Agric. Food Chem. 61:11453-9.

Migliorini P, Spagnolo S, Torri L, Arnoulet M, Lazzerini G, Ceccarelli S, 2016. Agronomic and quality characteristics of old, modern and mixture wheat varieties and landraces for organic bread chain in diverse environments of northern Italy. Eur. J. Agron. 79:131-41.

Singleton VL, Orthofer R, Lamuela-Raventos RM, 1999. Analysis of total phenols and other oxidation substrates and antioxidants by means of Folin-Ciocalteu reagent. Methods Enzymol. 29:152-78.

Singleton VL, Rossi JA, 1965. Colorimetry of total phenolics with phosphomolybdic-phosphotungstic acid reagents. Am. J. Enol. Vitic. 16:144-58.

Stagnari F, Galieni A, D’Egidio S, Falcinelli B, Pagnani G, Pace R, Pisante M, Benincasa P, 2017. Effects of sprouting and salt stress on polyphenol composition and antiradical activity of einkorn, emmer and durum wheat. Ital. J. Agron. 12:293-301.

Świeca M, Dziki D, Gawlik-Dziki U, 2017. Starch and protein analysis of wheat bread enriched with phenolics-rich sprouted wheat flour. Food Chem. 228:643-8.

Thaipong K, Boonprakob U, Crosby K, Cisneros-Zevallos L, Byrne DH, 2006. Comparisons of ABTS, DPPH, FRAP and ORAC assays for estimating antioxidant activity from guava fruit extracts. J. Food Compos. Anal. 19:669-75.

Turkmen N, Sari F, Velioglu S, 2005. The effect of cooking methods on total phenolics and antoxidant activity of selected green vegetables. Food Chem. 93:713-8.

van Boekel M, Fogliano V, Pellegrini N, Stanton C, Sholz G, Lalljie S, Somoza V, Knorr D, Jasti PR, Eisenbrand G, 2010. A review on the beneficial aspects of food processing. Mol. Nutr. Food Res. 54:1215-47.

Wong SP, Leong LP, Koh JHW, 2005. Antioxidant activities of aqueous extracts of selected plants. Food Chem. 99:775-83.

Yen GC, Chen HY, 1995. Antioxidant activity of various tea extracts in relation to their antimutagenicity. J. Agric. Food Chem. 43:27-32.

Yu L, Nanguet AL, Beta T, 2013. Comparison of antioxidant properties of refined and whole wheat flour and bread. Antioxidants 2:370-83.

Žilić S, Basić Z, Šukalović VHT, Maksimović V, Janković M, Filipović M, 2014. Can the sprouting process applied to wheat improve the contents of vitamins and phenolic compounds and antioxidant capacieties of the flour? Int. J. Food Sci. Technol. 49:1040-7. 